
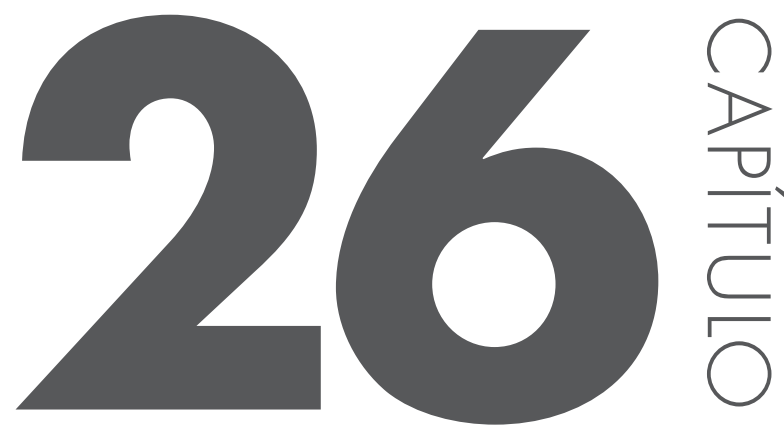

\title{
CONSIDERAC̣ÕES SOBRE MÉTODO E PESQUISA CIENTÍFICA NA GEOGRAFIA
}

Alves, Sandra Aparecida '; Mendonça, Marcelo 2; Avelar, Gilmar Alves ${ }^{3}$

1 Mestranda do Programa de Pós- Graduação da RC/UFG, Bolsista Capes

2 Professor dos Cursos de Pós- Graduação em Geografia PPGG RC e IESA/UFG

3 Professor do Instituto de Geografia RC/UFG

* email: sanddrap@hotmail.com

\section{RESUMO}

Trataremos neste ensaio sobre algumas questões sobre o método e a pesquisa científica na Geografia. Compreendemos que o método científico não são apenas os procedimentos e técnicas científicas, mas também é formado pela teoria que subsidia a realização da pesquisa. Essa teoria e esse caminho escolhido estão diretamente ligados à visão de mundo deste pesquisador, não existindo assim pesquisa neutra. Dessa forma, uma pesquisa realizada numa perspectiva teórica e metodológica rigorosa pode também ser engajada na realidade. $\mathrm{Na}$ Geografia se usa diferentes métodos científicos, sendo os principais o hipotético-dedutivo, o fenomenológico e o dialético, sendo que 
neste, utilizaremos o método dialético para realizar uma breve análise da ciência geográfica e da visão social de mundo construída pelo pesquisador em sua pesquisa.

Palauras-chave: Pesquisa; Método; Geografia 


\section{O MÉTOdO E A PESQUISA NA GEOGRAFIA}

O método e a pesquisa científica na Geografia são debates permanentes e de difícil trato, entretanto, necessários para o avanço da Ciência Geográfica e para os geógrafos, já que além de ser um processo de busca do conhecimento científico social é também uma opção ideológica do pesquisador ou da pesquisadora.

Assim, a pesquisa possivelmente refletirá a visão social de mundo (conjunto coerente de ideias sobre o homem, a sociedade, a história e a sua relação com a natureza) do pesquisador, ou seja, esta visão de mundo está vinculada a posições sociais ligadas a interesses de determinados grupos e classe social.

Realmente a seleção do objeto de pesquisa como a aplicação técnica das descobertas científicas depende dos interesses e concepções de classes e de grupos sociais que financiam, controlam e orientam a produção científico-natural, assim como da ideologia ou visão social de mundo dos próprios pesquisadores. Isso não vale apenas para os laboratórios das empresas privadas e para a pesquisa no campo dos armamentos, mas para o conjunto do sistema de produção de conhecimentos científicos na sociedade capitalista moderna. (LOWY, 1994, p. 199).

Nesse sentido, de uma forma geral, podemos afirmar que nas ciências da sociedade, não apenas o objeto da pesquisa, mas também o referencial teórico, a pesquisa empírica e os resultados são condicionados pelas opções ideológicas, mesmo que no seio de uma única ciência haja diferentes níveis de tensão ideológica.

Referente à ideologia, há algumas concepções cristalizadas. Primeiramente havia os ideólogos, que de forma grosseira, podemos dizer que a partir das ideias e da imaginação construíam teorias que buscavam “encaixar” no mundo real. Na maioria dos casos os ideólogos buscavam justificar a ação da burguesia. E foi nessa perspectiva que o pensamento dominante foi conceituado por Karl Marx como ideologia.

Mais tarde, Lênin conceituou ideologia como sendo uma forma de interpretar o mundo a partir da luta de classes. Dessa forma qual a ligação entre o método e a ideologia, já que a ciência é vista por várias correntes como uma forma neutra de interpretar o mundo?

Não existe neutralidade na ciência, já que a neutralidade é uma posição política que certamente beneficiará uma classe determinada. Assim, podese afirmar que não há intelectuais autônomos em relação à classe, já que a 
ideologia que eles produzem representa o pensamento de uma classe social. Lowy, (1994, p. 101), coloca bem essa questão, quando afirma que "[...] o que define uma ideologia (ou utopia) não é esta ou aquela ideia isolada, tomada em si própria, este ou aquele conteúdo doutrinário, mas uma certa "forma de pensar", uma certa problemática, um certo horizonte intelectual ("limites da razão")”. Lowy observa ainda que este raciocínio não se aplica somente aos literários e políticos, mas também aos cientistas e pesquisadores das diversas ciências.

Este raciocínio vale unicamente para os representantes políticos e literários de uma classe? Não se aplica ele também a seus representantes de uma classe? Não se aplicaria ele também a seus representantes científicos (ou com pretensão científica), no domínio das ciências sociais e econômicas? Realmente, o conceito de representação cientifica de classe ocupa um lugar crucial na crítica marxista da economia política. Na Miséria da Filosofia, Marx já escrevera que "os economistas são os representantes científicos da classe burguesa" - fórmula que sugere claramente que para ele ciência e representação de um ponto de vista de classe não são mutuamente exclusivos....Para ele estava em questão a economia política, mas nos parece que suas conclusões metodológicas essências são aplicáveis aos conjunto das ciências sociais. (LOWY, 1994, p. 102).

Desta forma, a ciência, produzida nas veias da classe burguesa, analisadas a partir do método marxista é vista a partir das concepções produzidas para servir aos interesses da classe dominante através da ciência que surge da ideologia de classes.

Essa concepção de mundo e metodológica foi importante na construção das ciências sociais, ou de correntes que buscavam o enfrentamento às ideologias capitalistas e de exploração à classe trabalhadora. No entanto, muitos pesquisadores ditos marxistas, por não ler ou não compreender o marxismo acabaram seguindo formulas ortodoxas (chamada de marxismo ortodoxo), construindo uma análise mecanicista, quase positivista. Essa forma de produzir o pensamento ortodoxamente não contribui mais para o avanço do pensamento das ciências sociais e nem da ciência geográfica, pois a luta de classes e a disputa ideológica não é apenas ideológica, ela se configura na vida concreta das classes sociais, ou seja, esquerda e direita não indica uma luta apenas ideológica (BOBBIO, 2001, p. 51). 
Para os pesquisadores militantes o método é um grande desafio já que se propõe como pesquisador a produzir ciência e não somente ideologia, mesmo sabendo que toda ciência está diretamente vinculada a uma ideologia é necessário ir além da aparência e construir ou comungar conceitos da classe trabalhadora que contribuirão na luta de classes, como advertiu Marx: toda luta revolucionária precisa de uma teoria revolucionária.

Diante desta questão, é necessário pensar enquanto pesquisador sobre o real proposito da geografia e nosso real proposito enquanto pesquisador dessa ciência. Aqui há que se aplicar nossa ideologia, afirmando que a ciência e a geografia buscam ontologicamente melhorar a vida da classe trabalhadora e camponesa, tornando essa a verdade a ser buscada. Claro que essa é uma verdade buscada a partir de uma visão de mundo, a partir de uma ideologia. Há outras.

Nós geógrafos devemos considerar as questões epistemológicas da ciência geográfica, buscando sempre relacionar os métodos científicos e a Geografia. As categorias e os conceitos fundamentais da Geografia, como região, paisagem, lugar, território e espaço devem guiar a reflexão teórica e metodológica da pesquisa, subsidiada por um método que permita ao pesquisador a realização da práxis, ou seja, da prática realizada a partir de uma reflexão teórica.

O método é uma palavra originária do grego e pode ser traduzida como caminho. Assim, quando falamos de método, estamos falando das bases teóricas que vamos trilhar, do caminho da pesquisa que cada um e cada uma enquanto pesquisador ou pesquisadora conseguirá expor a partir de sua visão de mundo, buscando realizar uma pesquisa rigorosa e engajada, se assim optar.

A Geografia, dividida entre Geografia Humana e Geografia Física nesse debate, torna-se dualista, já que muitos pesquisadores fogem para o debate físico como uma forma de desvalorização do papel da geografia enquanto ciência social. O que acaba empobrecendo o pensamento geográfico, tornando-o alvo de críticas.

Diante do debate estabelecido acerca do método, não há uma definição acerca das dificuldades em se desenvolver o método na pesquisa científica, mas sim, a busca da aplicação desse método tendo clara a ideologia de classe a que esse método serve, ou ainda como coloca Lowy "[...] a história da ciência não pode ser separada da história em geral, da história da luta de classes em particular" (1994, p. 105). Assim como a ciência, podemos afirmar que o pesquisador também "[...] não se move no espaço e no tempo de forma independente do movimento histórico concreto.” (LOWY, 1994, p. 105).

Dessa forma, pensar a Geografia a partir de seus paradigmas, sempre calcados em determinada ideologia, determinado posicionamento político, 
determinada corrente, nos fará chegar à conclusão de que o nascimento da ciência geográfica, ou da ciência moderna ocorreu para dar resposta e atender propósitos políticos definidos.

A ideologia possui um papel fundamental na construção da ciência, para Lowy (1994), a ideologia circunscreve seus limites, pois o pesquisador estará limitado ideologicamente e teoricamente a buscar as soluções as quais sua opção política defende. Essa limitação não impede o pesquisador de realizar e produzir conhecimentos científicos importantes, mas sempre limitadas à ideologia burguesa.

Horizonte, perspectiva, ponto de vista, campo de visibilidade: estas metáforas óticas não devem evidentemente ser compreendidas em um sentido literal; simplesmente elas permitem colocar em evidência que o conhecimento, o saber ("a visão") estão estreitamente ligados a posição social ("altura") do observador científico. (LOWY, 1994, p. 109).

Definir o método de pesquisa, então, perpassa pela ideologia de classe do pesquisador, ou seja, essa definição irá de acordo com a área de atuação do mesmo. Para Spósito (2004), a Geografia Crítica tem como princípio a geografia militante, que adota o método histórico dialético de análise, assim o espaço geográfico é analisado como produto social, já a Geografia Física que adota outros métodos de análise, que não o método marxista terá o espaço geográfico concebido a partir do método utilizado, que não será o mesmo da Geografia Crítica.

A ideologia dos pesquisadores será fundamental na escolha do método da pesquisa, já que a opção ou a negação de certos métodos está diretamente ligada à opção política ideológica a qual o pesquisador comunga.

Além desta questão, há também a crise da ciência Geográfica, o que lhe obriga a construir novos caminhos, novas respostas. Essas questões nos fazem refletir sobre qual a perspectiva da Geografia, já que diversas correntes a analisam, a interpretam e a criticam de acordo com sua visão de mundo. Assim vários enfoques conceituais diferentes e até divergentes são dados a Geografia, colocando-a muitas vezes em quadro confuso de análise.

Os métodos pelos quais os geógrafos, ou outros estudiosos podem optar são diversos, como o positivista, o materialismo histórico dialético, o fenomenológico, o hermenêutico, dentre outros. Pode-se dizer que o método é a forma de se buscar os resultados da pesquisa através de uma teoria que irá fundamentar o trabalho a ser desenvolvido.

$\mathrm{Na}$ história da construção da Geografia, Gomes (1996) coloca que no início essa ciência foi marcada pelos relatos de viagens não possuindo um arcabouço teórico que lhe conferisse uma identidade de ciência, no entanto, a 
necessidade de um método para sistematizar o conhecimento acumulado até então. Sistematizar já é fazer escolhas entre o que se julga ser ou não geografia.

Considerados os fundadores da geografia moderna Humboldt e Ritter, segundo Gomes (1996), pela primeira vez a geografia tem uma perspectiva de análise mais rigorosa, objetiva e geral, o que lhe permitiu ser considerada uma ciência positiva moderna.

Já Vidal de La Blache foi fundamental, já que valorizava o método e o colocava como fundamental para dar cientificidade à geografia, buscando fazer a interligação entre o geral e o particular. Para La Blache o Geral devia estar ligado ao particular e o particular ao geral, buscando assim a generalização das leis e a construção de uma ciência objetiva, sendo a região a síntese desses processos.

Essa objetividade refletiu mais tarde na geografia, através da Geografia Quantitativa ou Nova Geografia, pois o determinismo preenchido de novo conteúdo renasce com técnicas matemáticas, trazendo a geografia para o contexto cientifico global através dos métodos hipotéticos dedutivos. A Geografia Quantitativa vai permanecer dominante até a década de 1970 quando decai, mas não desaparece.

A Geografia Crítica a partir de então se torna uma corrente forte e fazendo duras criticas tanto a Geografia tradicional quanto a Geografia Quantitativa. A Geografia Crítica se aproxima muito do humanismo, havendo uma proximidade no que se refere à crítica ao positivismo, segundo Gomes

Por este aspecto, o materialismo histórico e o humanismo moderno partem de uma mesma critica a recusa da ciência positivista, e podem, sob alguns aspectos, ser considerados como perspectivas complementares. O materialismo histórico redescobriu a reflexividade de toda ação social e, por conseguinte, a importância de uma analise que leve em conta o valor e o antropocentrismo da vida social. Ao mesmo tempo, o humanismo se desembaraçou do idealismo e dos subjetivismo, que caracterizaram as primeiras analises, e recolocou a importância da existência material no centro das interpretações. (GOMES, 1996, p. 302).

A base fundamental da Geografia Humanista é a Fenomenologia que se insere no movimento de ruptura através do pós-modernismo, renovando a base crítica e também condenando a ciência racionalista.

Não diferente das demais ciências, a Geografia, segundo Gomes (1996) para por três fases fundamentais, que são definidas como clássica, moderna e 
contemporânea. A fase clássica durou até por volta do ano de 1874 quando se inicia a fase moderna onde a Geografia faz parte de uma organização educacional que vai até o ano de1945, quando inicia a fase atual contemporânea, a geografia se torna plena após a segunda guerra mundial.

A partir de então, a Geografia transita por um período de transição e rompimento com o padrão de conhecimento, onde a quantificação se torna fundamental em sua análise. Essa transformação da Geografia não passa com a perda do domínio da Nova Geografia, mas acaba se infiltrando na Geografia como um todo e tanto a Geografia Humanista quanto a Crítica vão criticar e mostrar esse processo.

Cabe ressaltar ainda que com a Nova Geografia, a Geografia Tradicional foi praticamente aniquilada, pois ela partiu de sua mesma base filosófica, o que não ocorreu com a Geografia Crítica e Humanista que se construíram sobre novas bases filosóficas. Apesar das duras criticas a Geografia Quantitativa ainda resiste como uma corrente de pensamento.

É importante destacar, que a Geografia é uma ciência em construção. O seu desenvolvimento é marcado por constantes transformações. Saez e Capel (1981), nos mostra bem isso quando afirma que "[...] la geografia há sido nueva en distintos momentos de sudesarrollo". A Geografia passa por momentos de transformação e rompimentos em sua construção enquanto ciência, e isso é indicado pelas diversas correntes que vão construindo, reconstruindo e desconstruindo o pensamento geográfico.

Para compreender esse processo de construção e desconstrução do pensamento geográfico é necessário compreender o processo histórico e teórico das principais correntes da Geografia, como a Nova Geografia, a Geografia Crítica e a Geografia Humanista.

Iniciemos pela Nova Geografia ou Geografia Quantitativa, já que a mesma na década de 1950 (segunda Guerra Mundial) trouxe grandes mudanças nas bases da Geografia, inclusive com recusa a dualidades como a existente entre as ciências naturais e sociais, pois em seu entendimento havia uma unidade da ciência, assim a mesma não poderia ser classificada como Geografia Física ou Humana, pois a ciência era única.

Com o fim da Segunda Guerra Mundial, diversos eram os problemas causados, dentre eles a necessidade de busca da superação da crise capitalista, o que a fez buscar a partir de então, um conhecimento formatado a partir dos sistemas matemáticos que homogeneizavam as ciências e as análises desenvolvidas. As fórmulas matemáticas garantiam uma linguagem formal, coerente e com rigor científico, o que garantiu a Geografia teorias e conceitos capazes de caminhar de um campo a outro. 
As principais escolas da geografia quantitativa no Brasil foram a Universidade de São Carlos, a Universidade Estadual de Júlio de Mesquita Filho - UNESP (Rio Claro/SP) e a Universidade Federal do Rio de Janeiro.

A Geografia Quantitativa está presente fortemente na cartografia através do sensoriamento remoto, dentre outras formas.

Já a Geografia Crítica é influenciada pelo método histórico dialético ou marxista que segundo Saez e Capel (1981) foi resultado de diversos pontos, como 1) um debate marxista que não defendia mais o Estado Soviético, após a morte de Stalin; 2) os diversos problemas sociais encontrados fez aumentar os movimentos libertários nas colônias europeias; 3) o aparecimento de movimentos sociais que nasceram a partir das contradições do capitalismo e empobrecimento das populações e da degradação ambiental. O aparecimento da Geografia Crítica se deu em 1969 nos Estados Unidos, mas foi na Europa que ela teve seu principal representante que foi Ives Lacoste.

No Brasil, a Geografia Crítica chegou ao final da década de 1970, tendo como marco o $3^{\circ}$ Encontro Nacional de Geografia de 1978 da AGB, e influenciou fortemente a geografia brasileira. É importante ressaltar que a Geografia Crítica só se estabeleceu no Brasil após o fim da ditadura militar, pois até então todo e qualquer pensamento marxista ou socialista eram perseguidos pelo governo militar. A partir de então, o marxismo foi usado para compreender o momento que se passou e o momento presente.

A Geografia Humanista foi definida por Mello (1990), como "sendo uma forma de compreender a multiplicidade dos acontecimentos da vida a partir dos valores e sentimentos das pessoas, evitando assim o esforço de se reduzir o mundo a leis, ou corpo teórico...”. Ela surge a partir de estudos da psicologia e do urbanismo cultural. Seu principal representante é Yi-FU Tuan.

Ainda segundo Mello (1990) a Geografia Humanista se baseou em suas análises em diversas tendências filosóficas, como a fenomenologia, o existencialismo, o idealismo e a hermenêutica. Essas tendências são a base da Geografia Humanista, no entanto, não há uma delimitação entre elas, ou seja, não é uma geografia fenomenológica, ou idealista, mas uma junção entre elas a partir de uma base existencialista. Assim, a linha geral se configura na forma de analisar os fatores de valorização do indivíduo e do subjetivismo.

Analisando o histórico das principais correntes da Geografia chegamos à conclusão, mais uma vez, que a Geografia passa permanentemente por um processo de renovação. Para Milton Santos o espaço social é histórico, fruto do trabalho da humanidade e dinâmico, assim, é também um espaço aberto para a ação transformadora. As relações sociais são produto da história e podem ser modificados, assim como a ciência geográfica. 
Compreendendo que fazer Geografia a partir do método dialético perpassa pelo confronto de ideias e do reconhecimento que qualquer pensamento é resultado da complexidade social, assim discutível.

Compreendendo que o objeto da Geografia é o espaço geográfico e um espaço geográfico resultado da construção histórica da humanidade, assim a abordagem acerca desse sujeito social a partir do método dialético perpassa por sua análise social e histórica.

Ao escolher a dialética é necessário compreender que objeto e sujeito são inseparáveis e assim homem e natureza forma uma única interface.

Nesse sentido acredito ser necessário desenvolver uma pesquisa que saia da aparência do espaço, que não cumpra apenas a parte descritiva, perceptiva ou ainda estatística, mas que consiga captar a essência.

Alcançar a totalidade da realidade, considerando as lutas camponesas e o papel das mulheres nessas lutas, a partir da diversidade da luta e das contradições e disparidades no espaço da pesquisa será fundamental para alcançar a realidade e sua dinâmica.

A criticidade proveniente do método dialético será aplicada a pesquisa na medida em que a análise do processo de produção do espaço não hegemônico avance e consiga alcançar a perspectiva da construção de uma nova realidade. Refletir sobre a realidade mediada pela exploração e pela opressão de classe e gênero e a partir dela vislumbrar uma nova realidade é necessário e possível.

Encerramos com a certeza de que assumir uma postura política e ideológica na pesquisa presume assumir também uma postura teórica e metodológica no desenvolvimento da pesquisa na ciência geográfica. Essa afirmação advém do fato de se saber onde queremos chegar e de onde se fala, ou melhor, com que se fala. Essa é uma escolha, uma opção política. 


\section{Title: Considerations Method and Scientific Research in Geography}

\section{Abstract}

We will address in this essay on some questions about the method and scientific research in Geography. We understand that the scientific method is not just the scientific procedures and techniques but is also formed by the theory that subsidizes the research. This theory and this chosen path are directly linked to the worldview of the researcher, so there is no neutral research. This, a survey conducted in a rigorous theoretical and methodological perspective can also be engaged in reality. In Geography using different scientific methods, the main ones being the hypothetical- deductive method, the phenomenological and dialectical, and in this, we will use the dialectical method to perform a brief analysis of geographical science and social worldview constructed by the researcher in his research.

Keywords: Research. Method. Geography 


\section{REFERÊNCIAS}

BOBBIO, N. Direita e Esquerda: razões e significados de uma distinção política. São Paulo: UNESP, 2001. CARLOS, A. F. A.. A Geografia Brasileira: algumas reflexões. In: Terra Livre, . São Paulo, ano18, v. 1, n 18, jan./jun. 2002.

CASTELLS, M. A era da informação: economia, sociedade e cultura. São Paulo: Paz e Terra, 1999.

CHESNAIS, F. A mundialização do Capital. São Paulo: Xamã, 1996.

CHRISTOFOLETTI, A. Perspectivas da Geografia. . São Paulo: Difel, 1980.

GOMES, P. C. da C. Geografia e Modernidade. Rio de Janeiro: BertrandBrasil, 1996.

LOWY, M. As Aventuras de Karl Marx contra o Barão de Munchhausen: marxismo e positivismo na sociologia do conhecimento. São Paulo: Cortez, 1994.

.MARX, K.;. ENGELS, F. A Ideologia Alemã. São Paulo: Martins Fontes, 2001.

MARX, K. Manuscritos econômico-filosóficos. São Paulo: Martins Fontes, 1987.

0 Capital: crítica da Economia Política. Tradução de Rubens Enderle. São Paulo: Boitempo, 2013. MELLO, J. B. F. de. Geografia Humanística: a perspectiva da experiência vivida e uma crítica radical ao positivismo. In: Revista Brasileira de Geografia. Rio de Janeiro: UFRJ, p. 91-115. 1990.

MORAES, A. C. R. Geografia: pequena história crítica. 20. ed. São Paulo: Annablume, 2005.

SANTOS, M. Por uma Geografia Nova. São Paulo: EDUSP, 2004.

. A Natureza do Espaço. São Paulo: EDUSP, 2004.

SAEZ, CAPEL, H. Filosofia y Ciencia em la Geografia Contemporânea. Barcanova, 1981.

SPÓSITO, E. S. Geografia e Filosofia: contribuição para o ensino do pensamento geográfico. São Paulo:

Editora UNESP, 2004. 